\title{
ANALISIS PENJADWALAN ULANG PENERBANGAN PESAWAT BOEING 737-900ER PADA PT. BATIK AIR DI BANDARA SOEKARNO-HATTA
}

\author{
${ }^{1}$ Henri Ponda, ${ }^{2 .}$ Joko Hardono, ${ }^{3}$ Dodi Gusnaldi Ibnu Maulana \\ ${ }^{1,2,3 .}$ Program Studi Teknik Industri, Fakultas Teknik \\ Universitas Muhammadiyah Tangerang \\ Jl. Perintis Kemerdekaan I/33, Cikokol, Kota Tangerang \\ Email : ${ }^{1}$ henri_ponda@umt.ac.id, ${ }^{2}$ jhardno@yahoo.com, ${ }^{3}$ dodigusniadi@gmailcom
}

\begin{abstract}
A b s trak
Setiap perusahaan penerbangan memerlukan penjadwalan yang tepat dan baik. Penjadwalan yang tepat akan mendukung pencapaian tujuan perusahaan, yakni memaksimalkan pendapatan. Salah satu cara untuk menyusun jadwal penerbangan yang baik adalah dengan meminimumkan waktu tunggu bandara, yaitu lamanya pesawat berada di darat menunggu untuk diterbangkan kembali. Penulisan laporan ini bertujuan untuk melakukan penjadwalan ulang berdasarkan waktu tunggu pesawat Boeing 737-900ER yang dioperasikan PT Batik Air. Metode studi kasus diterapkan dalam penulisan ini. Data yang digunakan adalah data sekunder berupa jadwal penerbangan Boeing 737-900ER pada tanggal 21 Juni sampai 10 Juli 2017. Bandara yang dilayani pesawat ini adalah Surabaya, Semarang, Banjarmasin, Denpasar, Manado, Ambon, dan Jayapura. Penjadwalan ulang dilakukan dengan menerapkan metode Hungarian. Hasil penelitian menunjukkan bahwa dengan menerapkan Metode Hungarian, waktu tunggu bandara secara keseluruhan dapat dipersingkat sebanyak 10.045 menit. Penghematan waktu tersebut dapat dilakukan di Bandara Cengkareng. Saat ini Batik Air mengoperasikan 4 pesawat jenis Boeing 737-900ER untuk melayani jalur penerbangan tersebut, tetapi dengan penghematan waktu tunggu bandara tersebut pihak Batik Air sebenarnya hanya membutuhkan 3 pesawat.
\end{abstract}

Kata Kunci : Penjadwalan ulang penerbangan, Boeing 737-900ER, waktu tunggu bandara, model penugasan, Metode Hungarian.

\section{PENDAHULUAN}

Jalur transportasi udara menjadi salah satu pintu masuk berkembangnya pasar bebas, hal ini mendorong pesatnya pertumbuhan jasa pelayanan penerbangan tidak terkecuali di Indonesia dan setiap perusahaan penerbangan memerlukan penjadwalan yang tepat dan baik. Dengan adanya penjadwalan yang tepat, maka tujuan perusahaan untuk mengoptimalkan pendapatan dapat tercapai.

Penjadwalan di PT. Batik Air didasarkan pada Pemasaran, kemampuan pesawat per hari, program perawatan, dan waktu operasi bandara. Karena waktu tunggu bandara bukan merupakan dasar dalam melakukan penjadwalan jalur penerbangan pada PT. Batik Air, maka berdasarkan latar belakang tersebut penulis tertarik untuk melakukan penjadwalan ulang jalur penerbangan berdasarkan waktu tunggu bandara dengan menerapkan metode hungarian.

Masalah penugasan berkaitan dengan keinginan perusahaan dalam mendapatkan pembagian atau alokasi tugas (penugasan) yang optimal, dalam arti apabila penugasan tersebut dapat memberikan keuntungan maka bagaimana alokasi tugas atau penugasan tersebut dapat memberikan keuntungan yang maksimal, begitu pula sebaliknya jika menyangkut biaya.

Berdasarkan pada uraian diatas maka dapat dirumuskan bagaimana mengoptimalkan penjadwalan jalur penerbangan pesawat Boeing 737-900ER dari Bandara Soekarno-Hatta dengan tujuan Surabaya, Semarang, Banjarmasin, Denpasar, Manado, Ambon, dan Jayapura dengan menggunakan jumlah pesawat yang tersedia dengan menimalisasi waktu tunggu bandara. 
Sedangkan tujuan penelitian ini adalah untuk mengetahui waktu yang optimal berdasarkan hasil penjadwalan ulang.

\section{METODE PENELITIAN}

Data-data yang digunakan adalah data sekunder yaitu data yang sudah tercatat dan diolah tempat usaha. Selain itu diperlukan data penunjang yang diperoleh dari hasil wawancara dan observasi.

Dalam melaksanakan penelitian ini, penulis melakukannya dengan cara menerapkan metodologi-metodologi. Adapun metodologi yang digunakandalam pendekatan sitem pelaksanaan dalam menyusun laporan kerja praktek berikut :

\section{a. Studi Literatur}

Dalam hal ini penulis megambil dan menggunakan beberapa buku sebagai sumber referensi dan membuat teori-teori yang sangat menunjang materi kerja praktek. Sehingga penulis dapat membuat laporan sesuai dengan yang diharapkan.

\section{b. Pengolahan Data dan Analisa}

Dalam hal ini dilakukan praktek secara nyata dalam meganalisis waktu tunggu bandara pesawat Boeing 737-900ER di PT. Batik Air

\section{HASIL DAN PEMBAHASAN}

Tabel pengalokasian akan di buat pada masing-masing kota yang di singgahi. Karena terdapat 11 kota yang disinggahi, maka akan di buat 11 tabel pengalokasian. Tahap pertama mencari nilai terkecil pada setiap baris. Setiap nilai pada baris akan dikurangkan dengan nilai terkecil baris tersebut, hal ini di lakukan untuk mendapatkan nilai 0 pada setiap baris dan kolom .

Selanjutnya setiap baris harus memiliki minimal satu nilai 0. Optimalisasi diperiksa dengan menarik garis horizontal atau vertiakal yang melewati sebanyak mungkin nilai 0 dalam setiap garisnya. Jumlah garis yang terbentuk hanya 9 , kurang dari jumlah baris adalah kolomnya, dengan demikian solusi optimal belum dapat diperoleh. Pertama-tama Metode Hungarian akan diterapkan pada tabel bandara Cengkareng (CGK).

Karena data yang di gunakan adalah waktu, maka data yang pertama di perlukan adalah jadwal keberangkatan dan kedatangan pesawat dari PT. Batik Air yang menggunakan pesawat Boeing 737-900ER. Berikut jadwal keberangkatan dan kedatangan pesawat Batik Air dengan jenis Boeing 737-900ER.

Tabel 1 Jadwal jalur penerbangan pesawat Batik Air type Boeing 737-900ER

\begin{tabular}{|c|c|c|c|c|c|}
\hline No. & Flight & Dari & Departure* & Ke & Arrival** $^{* * \mid}$ \\
\hline 1 & ID 6180 & CGK & $23: 55$ & DJJ & $7: 55$ \\
\hline 2 & ID 6181 & DJJ & $8: 45$ & CGK & $12: 15$ \\
\hline 3 & ID 6356 & CGK & $13: 00$ & SRG & $14: 05$ \\
\hline 4 & ID 6355 & SRG & $14: 50$ & CGK & $15: 55$ \\
\hline 5 & ID 6170 & CGK & $0: 30$ & AMQ & $6: 00$ \\
\hline 6 & ID 6171 & AMQ & $6: 50$ & CGK & $8: 20$ \\
\hline 7 & ID 6212 & CGK & $9: 30$ & BDJ & $12: 15$ \\
\hline 8 & ID 6213 & BDJ & $12: 55$ & CGK & $13: 45$ \\
\hline 9 & ID 6272 & CGK & $14: 30$ & MDC & $18: 50$ \\
\hline 10 & ID 6275 & MDC & $19: 40$ & CGK & $21: 55$ \\
\hline
\end{tabular}


Tabel 2 Jadwal jalur penerbangan pesawat Batik Air type Boeing 737-900ER (lanjutan)

\begin{tabular}{|c|c|c|c|c|c|}
\hline 11 & ID 6274 & CGK & $1: 55$ & MDC & $6: 05$ \\
\hline 12 & ID 6271 & MDC & $7: 45$ & CGK & $10: 05$ \\
\hline 13 & ID 6512 & CGK & $10: 55$ & DPS & $13: 55$ \\
\hline 14 & ID 6513 & DPS & $16: 50$ & CGK & $17: 40$ \\
\hline 15 & ID 6370 & CGK & $6: 00$ & SUB & $7: 30$ \\
\hline 16 & ID 6391 & SUB & $8: 20$ & CGK & $9: 50$ \\
\hline 17 & ID 6576 & CGK & $10: 30$ & SUB & $12: 00$ \\
\hline 18 & ID 6575 & SUB & $12: 50$ & CGK & $14: 20$ \\
\hline 19 & ID 6578 & CGK & $15: 10$ & SUB & $16: 40$ \\
\hline 20 & ID 7579 & SUB & $17: 30$ & CGK & $19: 00$ \\
\hline 21 & ID 8580 & CGK & $19: 30$ & SUB & $21: 00$ \\
\hline 22 & ID 6583 & SUB & $21: 45$ & CGK & $23: 15$ \\
\hline
\end{tabular}

(Sumber: Depco Lion Group)

Keterangan :

$$
\begin{aligned}
& \text { * waktu setempat } \\
& \text { ** waktu setempat }
\end{aligned}
$$

Keterangan mengenai kode bandara/kota di beberapa daerah :

CGK ; Cengkareng

SUB : Surabaya

SRG : Semarang

BDJ : Banjarmasin

DPS : Denpasar

MDC : Manado

AMQ : Ambon

DJJ : Jayapura

Perhitungan dimulai dengan membuat tabel penugasan seperti berikut :

\begin{tabular}{|c|c|c|c|c|c|c|c|c|c|c|c|}
\hline \begin{tabular}{|l}
\multicolumn{1}{|r}{ Ke } \\
Dari
\end{tabular} & 6181 & 6355 & 6171 & 6213 & 6275 & 6271 & 6513 & 6391 & 6575 & 7579 & 8583 \\
\hline 6180 & 700 & 480 & 935 & 610 & 120 & 830 & 375 & 845 & 575 & 295 & 40 \\
\hline 6356 & 55 & 1275 & 290 & 1405 & 915 & 185 & 1170 & 200 & 1370 & 1090 & 835 \\
\hline 6170 & 735 & 515 & 970 & 645 & 155 & 865 & 410 & 880 & 610 & 330 & 75 \\
\hline 6212 & 1275 & 1055 & 70 & 1185 & 695 & 1405 & 950 & 1420 & 1150 & 870 & 615 \\
\hline 6272 & 135 & 1355 & 370 & 45 & 995 & 265 & 1250 & 280 & 10 & 1170 & 915 \\
\hline 6274 & 820 & 600 & 1055 & 730 & 240 & 950 & 495 & 965 & 695 & 415 & 160 \\
\hline 6512 & 1360 & 1140 & 155 & 1270 & 780 & 50 & 1035 & 65 & 1235 & 955 & 700 \\
\hline 6370 & 1065 & 845 & 1300 & 975 & 485 & 1195 & 740 & 1210 & 940 & 660 & 405 \\
\hline 6576 & 1335 & 1115 & 130 & 1245 & 755 & 25 & 1010 & 40 & 1210 & 930 & 675 \\
\hline 6578 & 175 & 1395 & 410 & 85 & 1035 & 305 & 1290 & 320 & 50 & 1210 & 955 \\
\hline 8580 & 435 & 215 & 670 & 345 & 1295 & 565 & 110 & 580 & 310 & 30 & 1215 \\
\hline
\end{tabular}

Tabel 3 Waktu Tunggu Bandara “Dari dan Mejunu”Bandara Cengkareng (CGK)

\section{Keterangan :}

$\square=$ Merupakan nilai terkecil dari setiap baris, yang nanntinya nilai terkecil ini menjadi angka yang di kurangkan dari setiap angka-angka lain pada baris tersebut 
Cara memperoleh angka-angka yang ada pada tabel $\mathbf{3}$ adalah sebaga berikut :

Data awal yang diproleh seperti yang terlihat pada tabel $1 \& 2$ merupakan data waktu atau jadwal keberangkatan dan kedatangan pesawat Batik Air jenis Boeing 737-900ER. Maka untuk selanjutnya harus mengkonversi kedalam satuan menit,

Contohnya untuk mendapatkan angka 700 menit seperti yang ada pada tabel $\mathbf{3}$ merupakan data yang diperoleh dari penerbangan Batik Air dengan nomor penerbangan :

a. ID 6180 dari Cengkareng (CGK) menuju Jayapura (DJJ), dan

b. ID 6181 dari Jayapura (DJJ) menuju Cengkareng (CGK)

karena penulis ingin mengetahui waktu tunggu bandara di Cengkareng, seperti pada tabel 3 maka waktu yang di hitung adalah waktu keberangkatan dari Cengkareng di kurangkan dengan waktu kedatangan di Cengkareng

a. ID 6180 dengan waktu keberangkatan dari Cengkareng adalah 23.55 WIB.

b. ID 6181 dengan waktu kedatangan di Cengkareng adalah 12.15 WIB

Maka jika di konversi ke satuan menit akan diproleh :

a. ID $6180=1435$ menit

b. $\quad$ ID $6181=735$ menit

Jika dikurangkan, $1435-735=700$ menit

Jadi angka 700 (menit) adalah hasil dari waktu antara ID 6180 dengan ID 6181

Langkah selanjutnya adalah Mencari waktu terkecil untuk setiap baris, kemudian menggunakannya untuk mengurangi semua waktu yang ada pada baris yang sama. Dengan langkah ini, maka diperoleh hasil seperti pada tabel 4 .

Tabel 4 hasil dari waktu terkecil dari setiap baris

\begin{tabular}{|c|c|c|c|c|c|c|c|c|c|c|c|}
\hline \begin{tabular}{|l|}
\multicolumn{1}{|r}{$\mathrm{Ke}$} \\
Dari \\
\end{tabular} & 6181 & 6355 & 6171 & 6213 & 6275 & 6271 & 6513 & 6391 & 6575 & 7579 & 8583 \\
\hline 6180 & 660 & 440 & 895 & 570 & 80 & 790 & 335 & 805 & 535 & 255 & 0 \\
\hline 6356 & 0 & 1220 & 235 & 1350 & 860 & 130 & 1115 & 145 & 1315 & 1035 & 780 \\
\hline 6170 & 660 & 440 & 895 & 570 & 80 & 790 & 335 & 805 & 535 & 255 & 0 \\
\hline 6212 & 1205 & 985 & 0 & 1115 & 625 & 1335 & 880 & 1350 & 1080 & 800 & 545 \\
\hline 6272 & 125 & 1345 & 360 & 35 & 985 & 255 & 1240 & 270 & 0 & 1160 & 905 \\
\hline 6274 & 660 & 440 & 895 & 570 & 80 & 790 & 335 & 805 & 535 & 255 & 0 \\
\hline 6512 & 1310 & 1090 & 105 & 1220 & 730 & 0 & 985 & 15 & 1185 & 905 & 650 \\
\hline 6370 & 660 & 440 & 895 & 570 & 80 & 790 & 335 & 805 & 535 & 255 & 0 \\
\hline 6576 & 1310 & 1090 & 105 & 1220 & 730 & 0 & 985 & 15 & 1185 & 905 & 650 \\
\hline 6578 & 125 & 1345 & 360 & 35 & 985 & 255 & 1240 & 270 & 0 & 1160 & 905 \\
\hline 8580 & 405 & 185 & 640 & 315 & 1265 & 535 & 80 & 550 & 280 & 0 & 1185 \\
\hline
\end{tabular}

Pada tabel 4 di peroleh nilai nol (0) dari setiap baris, selanjutnya memastikan semua baris dan kolom sudah memiliki nilai nol. Dan ternyata pada kasus ini masih terjadi bentrok atau masih ada kolom yang belum memiliki nol, yakni kolom 2,4,5,7 dan 8. Dengan demikian perlu dicari lagi nilai terkecil pada kolom tersebut untuk selanjutnya digunakan untuk mengurangi semua nilai yang ada pada kolom tersebut. Dengan langkah ini, maka diperoleh hasil : 
Tabel 5 nilai nol sudah ada pada setiap baris dan kolom

\begin{tabular}{|c|c|c|c|c|c|c|c|c|c|c|c|}
\hline \begin{tabular}{|l}
\multicolumn{1}{|r}{ Ke } \\
Dari
\end{tabular} & 6181 & 6355 & 6171 & 6213 & 6275 & 6271 & 6513 & 6391 & 6575 & 7579 & 8583 \\
\hline 6180 & 660 & 255 & 895 & 535 & 0 & 790 & 255 & 790 & 535 & 255 & 0 \\
\hline 6356 & 0 & 1035 & 235 & 1315 & 780 & 130 & 1035 & 130 & 1315 & 1035 & 780 \\
\hline 6170 & 660 & 255 & 895 & 535 & 0 & 790 & 255 & 790 & 535 & 255 & 0 \\
\hline 6212 & 1205 & 800 & 0 & 1080 & 545 & 1335 & 800 & 1335 & 1080 & 800 & 545 \\
\hline 6272 & 125 & 1160 & 360 & 0 & 905 & 255 & 1160 & 255 & 0 & 1160 & 905 \\
\hline 6274 & 660 & 255 & 895 & 535 & 0 & 790 & 255 & 790 & 535 & 255 & 0 \\
\hline 6512 & 1310 & 905 & 105 & 1185 & 650 & 0 & 905 & 0 & 1185 & 905 & 650 \\
\hline 6370 & 660 & 255 & 895 & 535 & 0 & 790 & 255 & 790 & 535 & 255 & 0 \\
\hline 6576 & 1310 & 905 & 105 & 1185 & 650 & 0 & 905 & 0 & 1185 & 905 & 650 \\
\hline 6578 & 125 & 1160 & 360 & 0 & 905 & 255 & 1160 & 255 & 0 & 1160 & 905 \\
\hline 8580 & 405 & 0 & 640 & 280 & 1185 & 535 & 0 & 535 & 280 & 0 & 1185 \\
\hline
\end{tabular}

Langkah berikutnya yaitu memastikan atau mengecek pada tabel penugasan tersebut, apakah sudah memiliki nilai nol yang sesuai dengan jumlah sumber daya, yang juga tercermin dengan jumlah barisnya. Misal, jika yang ditugaskan adalah 11 Pesawat, maka harus ditemukan nilai nol sebanyak 11 buah yang terletak di baris dan kolom berbeda. dimulai dari baris yang hanya memiliki satu nilai nol. Langkah ini mengandung arti bahwa setiap Pesawat hanya dapat memegang satu penugasan.

Karena dirasa kurang optimal maka langkah selanjutnya adalah menarik garis yang menghubungkan minimal dua buah nilai nol, seperti diperlihatkan pada tabel 6 di bawah ini:

Tabel 6 menarik garis untuk setiap baris dan kolom yang memiliki nilai nol

\begin{tabular}{|c|c|c|c|c|c|c|c|c|c|c|c|}
\hline Dari & 6181 & 6355 & 6171 & 6213 & 6275 & 6271 & 6513 & 6391 & 6575 & 7579 & 8583 \\
\hline 6180 & 660 & 255 & 895 & 535 & 0 & 790 & 255 & 790 & 535 & 255 & 0 \\
\hline 6356 & 0 & 1035 & 235 & 1315 & 780 & 130 & 1035 & 130 & 1315 & 1035 & 780 \\
\hline 6170 & 660 & 255 & 895 & 535 & 0 & 790 & 255 & 790 & 535 & 255 & 0 \\
\hline 6212 & 1205 & 800 & 0 & 1080 & 545 & 1335 & 800 & 1335 & 1080 & 800 & 545 \\
\hline 6272 & 125 & 1160 & 360 & 0 & 905 & 255 & 1160 & 255 & 0 & 1160 & 905 \\
\hline 6274 & 660 & 255 & 895 & 535 & 0 & 790 & 255 & 790 & 535 & 255 & 0 \\
\hline 6512 & 1310 & 905 & 105 & 1185 & 650 & 0 & 905 & 0 & 1185 & 905 & 650 \\
\hline 6370 & 660 & 255 & 895 & 535 & 0 & 790 & 255 & 790 & 535 & 255 & 0 \\
\hline 6576 & 1310 & 905 & 105 & 1185 & 650 & 0 & 905 & 0 & 1185 & 905 & 650 \\
\hline 6578 & 125 & 1160 & 360 & 0 & 905 & 255 & 1160 & 255 & 0 & 1160 & 905 \\
\hline 8580 & 405 & 0 & 640 & 280 & 1185 & 535 & 0 & 535 & 280 & 0 & 1185 \\
\hline
\end{tabular}

Dari langkah di atas terlihat bahwa garis yang berhasil dibuat adalah sembilan buah, dengan menyisakan beberapa nilai yang tidak terkena garis.

Dari tabel 6 ada beberapa nilai-nilai yang belum terkena garis. Selanjutnya pilih nilai yang paling kecil, dari tabel di atas adalah nilai 255, kemudian nilai 255 tersebut dipergunakan untuk mengurangi nilai-nilai lain yang belum terkena garis, dan gunakan untuk menambah nilainilai yang terkena garis ganda. Dengan langkah ini, maka diperoleh hasil yang diperlihatkan pada tabel 7. 
Tabel 7 nilai nol sudah terdapat 11 buah pada setiiap baris dan kolom yang berbeda

\begin{tabular}{|c|c|c|c|c|c|c|c|c|c|c|c|}
\hline \begin{tabular}{|l}
\multicolumn{1}{|r}{ Ke } \\
Dari
\end{tabular} & 6181 & 6355 & 6171 & 6213 & 6275 & 6271 & 6513 & 6391 & 6575 & 7579 & 8583 \\
\hline 6180 & 405 & 0 & 640 & 280 & 0 & 535 & 0 & 535 & 280 & 0 & 0 \\
\hline 6356 & 0 & 1035 & 235 & 1315 & 1035 & 130 & 1035 & 130 & 1315 & 1035 & 1035 \\
\hline 6170 & 405 & 0 & 360 & 280 & 0 & 535 & 0 & 535 & 280 & 0 & 0 \\
\hline 6212 & 1205 & 800 & 0 & 1080 & 800 & 1335 & 800 & 1335 & 1080 & 800 & 800 \\
\hline 6272 & 125 & 1160 & 360 & 0 & 1160 & 255 & 1160 & 255 & 0 & 1160 & 1160 \\
\hline 6274 & 405 & 0 & 640 & 280 & 0 & 535 & 0 & 535 & 280 & 0 & 0 \\
\hline 6512 & 1310 & 905 & 105 & 1185 & 905 & 0 & 905 & 0 & 1185 & 905 & 905 \\
\hline 6370 & 405 & 0 & 640 & 280 & 0 & 535 & 0 & 535 & 280 & 0 & 0 \\
\hline 6576 & 1310 & 905 & 105 & 1185 & 905 & 0 & 905 & 0 & 1185 & 905 & 905 \\
\hline 6578 & 125 & 1160 & 360 & 0 & 1160 & 255 & 1160 & 255 & 0 & 1160 & 1160 \\
\hline 8580 & 405 & 0 & 640 & 280 & 1440 & 535 & 0 & 535 & 280 & 0 & 1440 \\
\hline
\end{tabular}

Pada tabel 7 di atas sudah berhasil ditemukan 11 buah nilai nol (sejumlah rute yang akan ditugaskan), yang berada di baris dan kolom berbeda, artinya tabel penugasan di atas sudah optimal.

Tabel 8 Tabel Optimal

\begin{tabular}{|c|c|c|c|c|c|c|c|c|c|c|c|}
\hline $\begin{array}{ll} & \mathrm{Ke} \\
\text { Dari } & \end{array}$ & 6181 & 6355 & 6171 & 6212 & 6275 & 6271 & 6513 & 6391 & 6575 & 7579 & 8583 \\
\hline 6180 & 0 & 0 & 0 & 0 & 0 & 0 & 0 & 0 & 0 & 0 & 8 \\
\hline 6356 & 1 & 0 & 0 & 0 & 0 & 0 & 0 & 0 & 0 & 0 & 0 \\
\hline 6170 & 0 & 0 & 0 & 0 & 9 & 0 & 0 & 0 & 0 & 0 & 0 \\
\hline 6212 & 0 & 0 & 2 & 0 & 0 & 0 & 0 & 0 & 0 & 0 & 0 \\
\hline 6272 & 0 & 0 & 0 & 0 & 0 & 0 & 0 & 0 & 3 & 0 & 0 \\
\hline 6274 & 0 & 0 & 0 & 0 & 0 & 0 & 0 & 0 & 0 & 10 & 0 \\
\hline 6512 & 0 & 0 & 0 & 0 & 0 & 5 & 0 & 0 & 0 & 0 & 0 \\
\hline 6370 & 0 & 0 & 0 & 0 & 0 & 0 & 11 & 0 & 0 & 0 & 0 \\
\hline 6576 & 0 & 0 & 0 & 0 & 0 & 0 & 0 & 4 & 0 & 0 & 0 \\
\hline 6578 & 0 & 0 & 0 & 6 & 0 & 0 & 0 & 0 & 0 & 0 & 0 \\
\hline 8580 & 0 & 7 & 0 & 0 & 0 & 0 & 0 & 0 & 0 & 0 & 0 \\
\hline
\end{tabular}

Keterangan :

\section{= Daerah arsiran tersebut merupakan pasangan nomor penerbangan}

Dari tabel diatas dapat kita tentukan kesebelas pasangan nomor penerbangan tersebut adalah :

Tabel 9 pasangan nomor penerbangan dari dan menuju Cengkareng

\begin{tabular}{|lll|lll|}
\hline ID 6583 & - & ID 6180 & ID 6271 & - & ID 6512 \\
ID 6181 & - & ID 6356 & ID 6513 & - & ID 6370 \\
ID 6275 & - & ID 6170 & ID 6391 & - & ID 6576 \\
ID 6171 & - & ID 6212 & ID 6213 & - & ID 6578 \\
ID 6575 & - & ID 6272 & ID 6355 & - & ID 8580 \\
ID 7579 & - & ID 6274 & & & \\
\hline
\end{tabular}

JIM, Vol. 3, No. 2, Juli 2018, pp.23-32 
Sehingga dari tabel 9 dapat disimpulkan :

Bahwa setiap nomor penrbangan sudah memiliki penugasan yang optimal seperti yang ada pada tabel 9.

Dengan cara dan teknik yang sama diperoleh pasangan nomor penerbangan untuk masing-masing kota seperti yang ditunjukan tabel $\mathbf{1 0 .}$

Tabel 10 Pasangan nomor penerbangan dari dan menuju kota lain

\begin{tabular}{|c|c|c|c|}
\hline \multicolumn{2}{|c|}{ Surabaya (SUB) } & \multicolumn{2}{|c|}{ Manado (MDC) } \\
\hline ID 6370 & - $\quad$ ID 6391 & ID 6272 & ID 6275 \\
\hline ID 6575 & - $\quad$ ID 6576 & ID 6274 & - $\quad$ ID 6271 \\
\hline ID 7579 & - $\quad$ ID 6578 & \multicolumn{2}{|c|}{ Semarang (SRG) } \\
\hline ID 6853 & - $\quad$ ID 8580 & ID 6356 & ID 6355 \\
\hline \multicolumn{2}{|c|}{ Ambon (AMQ) } & \multicolumn{2}{|c|}{ Jayapura (DJJ) } \\
\hline ID 6170 & - $\quad$ ID 6171 & ID 6180 & - $\quad$ ID 6181 \\
\hline \multicolumn{2}{|c|}{ Banjarmasin (BDJ) } & \multicolumn{2}{|c|}{ Denpasar (DPS) } \\
\hline ID 6212 & - $\quad$ ID 6213 & ID 6512 & ID 6513 \\
\hline
\end{tabular}

Adapun urutan nomor penerbangan yang baru berdasarkan data yang di dapatkan pada operasi hitung di atas adalah sebagai berikut :

1. ID6181-ID6356 / ID6355-ID 8580 / ID 6583-6180

2. ID6170-ID6171 / ID6212-ID6213 / ID6578-ID7797 / ID6274-ID6271 / ID6512-ID6513

3. ID6370-ID6391 / ID6576-ID6575 / ID6272-ID6275

Berikut jadwal jalur penerbangan pesawat Batik Air dengan jenis Boeing 737-900ER.

Tabel 11 Jadwal Jalur Penerbangan Pesawat Batik Air jenis Boeing 737-900ER

\begin{tabular}{|c|c|c|c|c|c|}
\hline No. & Flight & Dari & Departure* & Ke & Arrival** $^{* * \mid}$ \\
\hline 1 & ID 6180 & CGK & $23: 55$ & DJJ & $7: 55$ \\
\hline 2 & ID 6181 & DJJ & $8: 45$ & CGK & $12: 15$ \\
\hline 3 & ID 6356 & CGK & $13: 00$ & SRG & $14: 05$ \\
\hline 4 & ID 6355 & SRG & $14: 50$ & CGK & $15: 55$ \\
\hline 5 & ID 6170 & CGK & $0: 30$ & AMQ & $6: 00$ \\
\hline 6 & ID 6171 & AMQ & $6: 50$ & CGK & $8: 20$ \\
\hline 7 & ID 6212 & CGK & $9: 30$ & BDJ & $12: 15$ \\
\hline 8 & ID 6213 & BDJ & $12: 55$ & CGK & $13: 45$ \\
\hline 9 & ID 6272 & CGK & $14: 30$ & MDC & $18: 50$ \\
\hline 10 & ID 6275 & MDC & $19: 40$ & CGK & $21: 55$ \\
\hline 11 & ID 6274 & CGK & $1: 55$ & MDC & $6: 05$ \\
\hline 12 & ID 6271 & MDC & $7: 45$ & CGK & $10: 05$ \\
\hline 13 & ID 6512 & CGK & $10: 55$ & DPS & $13: 55$ \\
\hline 14 & ID 6513 & DPS & $16: 50$ & CGK & $17: 40$ \\
\hline 15 & ID 6370 & CGK & $6: 00$ & SUB & $7: 30$ \\
\hline 16 & ID 6391 & SUB & $8: 20$ & CGK & $9: 50$ \\
\hline 17 & ID 6576 & CGK & $10: 30$ & SUB & $12: 00$ \\
\hline 18 & ID 6575 & SUB & $12: 50$ & CGK & $14: 20$ \\
\hline 19 & ID 6578 & CGK & $15: 10$ & SUB & $16: 40$ \\
\hline 20 & ID 7579 & SUB & $17: 30$ & CGK & $19: 00$ \\
\hline 21 & ID 8580 & CGK & $19: 30$ & SUB & $21: 00$ \\
\hline 22 & ID 6583 & SUB & $21: 45$ & CGK & $23: 15$ \\
\hline
\end{tabular}




\section{Menghitung Total WaktuTunggu Bandara pada Setiap Bandara}

Setelah setiap pasangan nomor penerbangan di dapat, langkah selanjutnya adalah menghitung total waktu tunggu bandara pada setiap bandara.

- Bandara Cengkareng

$$
\begin{aligned}
Z & =55+215+70+85+155+50+740+40+10+415+40 \\
& =1875 \text { menit }
\end{aligned}
$$

Dengan cara dan teknik yang sama di dapat perbandingan antara waktu tunggu bandara berdasarkan jadwal lama dan jadwal baru setelah diterapkan Metode Hungarian :

Tabel 12 Perbandingan waktu tunggu bandara Antara Jadwal Lama dengan Jadwal Baru

\begin{tabular}{|c|c|c|}
\hline Kota & Jadwal Baru & Jadwal lama \\
\hline Cengkareng & 1875 & 11920 \\
\hline Surabaya & 195 & 195 \\
\hline Semarang & 45 & 45 \\
\hline Banjarmasin & 40 & 40 \\
\hline Manado & 150 & 150 \\
\hline Denpasar & 175 & 175 \\
\hline Ambon & 50 & 50 \\
\hline Jayapura & 50 & 50 \\
\hline
\end{tabular}

Jika dilakukan perincian terhadap masing masing nomor penerbangan maka setiap pesawat pada masing masing bandara di tiap kota yang menjalani waktu tunggu bandara maka waktu tunggu bandara pada masing masing kota untuk jadwal baru jika dibandingkan dengan jadwal lama adalah sebagai berikut :

Tabel 13 Perbandingan waktu tunggu bandara Antara Jadwal Lama dengan Jadwal Baru

\begin{tabular}{|c|c|c|}
\hline Kota & Jadwal Baru & Jadwal lama \\
\hline Cengkareng & $1875 /(4 * 22)=21,3$ & $11920 /(4 * 22)=135,45$ \\
\hline Surabaya & $195 /(4 * 8)=6,09$ & $195 /(4 * 8)=6,09$ \\
\hline Semarang & $45 /(4 * 2)=5,62$ & $45 /(4 * 2)=5,62$ \\
\hline Banjarmasin & $40 /(4 * 2)=5$ & $40 /(4 * 2)=5$ \\
\hline Manado & $150 /(4 * 4)=9,37$ & $150 /(4 * 4)=9,37$ \\
\hline Denpasar & $175 /(4 * 2)=21,87$ & $175 /(4 * 2)=21,87$ \\
\hline Ambon & $50 /(4 * 2)=6,25$ & $50 /(4 * 2)=6,25$ \\
\hline Jayapura & $50 /(4 * 2)=6,25$ & $50 /(4 * 2)=6,25$ \\
\hline
\end{tabular}


Perbedaan antara jadwal baru dan jadwal lama pada bandara Cengkareng jika dilihat pada tabel 12 adalah 10045 menit dan pada tabel 13 dapat dibuktikan sebagai berikut:

Cengkareng :

$=135,45-21,3=114,15$ menit,

$=114,15 *(4 * 22)=10.045$ menit (terbukti)

\section{KESIMPULAN}

Berdasarkan hasil pengolahan data diatas menunjukan bahwa dengan menerapkan Metode Penugasan, waktu tunggu bandara dapat dipersingkat sebanyak 10.045 menit, penghematan tersebut dapat dilakukan di Bandara Cengkareng. Saat ini Batik Air mengoperasikan 4 pesawat untuk melyani jalur penerbnagan tersebut, tapi dengan penghematan waktu tersebut pihak Batik Air hanya membutuhkan 3 pesawat

\section{SARAN}

Dari hasil laporan dan pemaparan yang sudah jelaskan di atas, berikut adalah saran yang ingin diberikan baik untuk penulisan selanjutnya maupun bagi perusahaan. Semoga dengan saran ini, akan menjadikan lebih bak untuk kedepannya.

1. Sebaiknya waktu tunggu bandara di perhatikan lagi, karna selain untuk ketepatan waktu pesawat untuk di terbangkan kembali, dan megurangi resiko delay pada pesawat, waktu tunggu bandara juga dapat meningkatkan profit pada perusahaan.

2. Metode ini dapat digunakan untuk melakukan penjadwalan ulang untuk rute yang lainnya.

\section{DAFTAR PUSTAKA}

Aras A., Dkk. (2016). Optimalisasi Pendapatan Pada CV. Palunesa Collection Team dengan Menggunakan Metode Hungarian. JIMT Vol. 12 No. 2 Desember 2016 (Hal 172 - 184).

Bahrawi A. (2007). Angkutan Penumoang Pesawat Udara diakitkan dengan Perkembangan perusahaan Penerbangan Berbiaya Murah: Studi Kasus Provinsi Sumatera Utara. Jurnal Transportasi Vol. 7 No. 1 Juni 2007: 67-78.

Lemantara J., dan Windarti T. (2014). Sistem Pendukung Keputusan Pengoptimalan Pembagian Tugas dengan Metode Assignment Berbasis Web, JNTETI, Vol. 3, No. 4, November 2014 , pp. $248-255$.

Sarjono H., Dkk. (2013). Penerapan Metode Hungarian pada Perusahaan Jasa (Kasus Minimum). BINUS BUSINESS REVIEW Vol. 4 No. 2 November 2013: 812-820.

Siswanto. (2007) Operational Research. Bogor : Penerbit Erlangga.

Subagyo, P., Dkk. (1991) Dasar-Dasar Operations Research. Yogyakarta : BPFE. 
